\title{
Assisted suicide: why psychiatrists should engage in the debate
}

Matthew Hotopf, William Lee and Annabel Price

\begin{abstract}
Summary
There is an increasing appetite for a change in the law to allow assisted suicide. This editorial suggests that

psychiatrists should engage in the debate because the issues at stake will affect us, and we are likely to have a significant part to play were the law to be changed. We suggest that there are three main areas where psychiatrists' expertise may be informative: (a) the extent to which safeguards to limit the availability of assisted dying to target groups can be applied safely and fairly, including to individuals with psychiatric disorders; (b) the complexities inherent in assessing mental capacity; and (c) the degree to which
\end{abstract}

individuals adapt or change their desires, particularly in relation to suicidal behaviours.

\section{Declaration of interest}

M.H. is an honorary consultant psychiatrist at St Christopher's Hospice, who pay $10 \%$ of his salary. W.L. has been employed as a lecturer in palliative care psychiatry by King's College London, Institute of Psychiatry, a post supported by St Christopher's Hospice. A.P. is currently employed on the same post. The authors do not hold any religious views which prohibit assisted suicide.
Matthew Hotopf (pictured) is Professor of General Hospital Psychiatry, William Lee is MRC Clinical Training Fellow and Annabel Price is Lecturer in Psychiatry at the Department of Psychological Medicine, Institute of Psychiatry, King's College London, UK.

Recent high-profile cases have provided fuel for demands for a change in the law on assisted suicide. ${ }^{1}$ A private member's Bill advocating such a change was brought before the Scottish Parliament last year by Margo MacDonald MSP (but fell at the Stage 1 debate). ${ }^{2}$ Lord Joffe's most recent attempt to change the law in England and Wales was rejected by the House of Lords in $2006,{ }^{3}$ but it is likely there will be further attempts. ${ }^{4}$ The Director of Public Prosecutions recently issued new guidance on the matter. While re-emphasising the illegality of assisting suicide, it also stated the circumstances under which a prosecution would be unlikely. ${ }^{5}$ This position has been criticised as an unacceptable compromise, being on the one hand worse than a full criminal investigation, and on the other, the effective legalisation of assisted dying. ${ }^{6}$

In this editorial we argue that psychiatrists need to inform the debate, not least because we would certainly be agents in the process by which assisted suicide is 'delivered'. Lord Joffe's Bills explicitly mention this and the Scottish Bill insists on psychiatric assessment as part of the process. We do not seek to provide a comprehensive review of the rights and wrongs of assisted suicide, but to explore some of the issues in the debate on which psychiatrists might legitimately contribute.

At present, the law recognises a distinction between withdrawal of life-sustaining treatment (which is legal) and active measures to bring about death (which is not). Assisted suicide is the provision of a means of suicide which would allow an individual to take their own life. Euthanasia goes further where another party takes the action which brings about death. In England, assisting suicide is prohibited by the Suicide Act (1961), with a maximum jail term of 14 years. Lord Joffe's and Ms MacDonald's proposals both place a number of safeguards on the restriction of the legal use of assisted suicide. These include: that the person involved has mental capacity; that he or she experiences unbearable suffering; and that he or she is suffering from a terminal illness with a limited life expectancy (or in the Scottish Bill, is physically incapacitated and cannot live independently).

\section{How inclusive should legislation be?}

One objection to assisted suicide is the so-called 'slippery slope' argument - that is, that it would be difficult to restrict its use to the originally intended groups. It is striking that some individuals who have recently sought assisted suicide from the Swiss organisation Dignitas would have been excluded by one or both of the proposed legislative changes, including people with early cancer, a young man with a spinal cord injury leading to tetraplegia, and people who anticipate their life becoming intolerable in the future. It is impossible not to be sympathetic to the plight of many whose cases have been described in the media. But if one were sympathetic to a change in the law, how could a new line of eligibility be drawn which would be equitable and safe? If one sees assisted suicide as a right for individuals facing intolerable suffering, why restrict its use to those with a life-limiting illness or who cannot live independently? The case of Lynn Gilderdale, a woman who was assisted in her suicide by her mother and who had chronic fatigue syndrome, illustrates this problem. The case was portrayed in the media as a logical course of action, despite the diagnosis being based on medically unexplained symptoms, the life expectancy being similar to that of the general population ${ }^{7}$ and the condition being potentially treatable. ${ }^{8}$ Further, why not make assisted suicide available to those with chronic mental disorders, whose conditions may arguably be associated with greater suffering, who may have intractable symptoms, and who may arguably have a poorer quality of life than many individuals with cancer, but who do not have a poor prognosis or need daily help? Restricting a change in the legislation to those with limited life expectancy or physical incapacity would fail to address the apparent needs of many who currently seek assisted suicide.

\section{Mental capacity}

Another proposed safeguard would be that patients requesting assisted suicide should have the mental capacity to do so. The Mental Capacity Act 2005 for England and Wales makes clear that capacity should be presumed and that individuals have a right to make unwise decisions. Clearly, it would be wrong to state that 
someone, by virtue of making a decision of which others disapprove, automatically lacks capacity. The task of assessing mental capacity, especially if in doubt, would fall to psychiatrists. However, this raises a set of issues around the definition of mental capacity, particularly when a decision seems to be influenced by psychopathology rather than cognitive impairments. In a different context, the concept of mental capacity as a global framework for compulsory treatment has been criticised by some for being too dominated by the cognitive capacities. ${ }^{9}$ The Mental Capacity Act requires the individual to understand and retain the information necessary to make a decision, as well as to use and weigh that information. Most psychiatric practice takes place with individuals whose decision-making difficulties are in the more nebulous 'use and weigh' area. This criterion is difficult to operationalise. When would a patient with depression, who believes that their life is not worth living, that they should stop being a burden to their family, and should thus receive assisted suicide, be making an incapacitous decision? Are the apparently 'pathological' values held by individuals with eating disorders, such that it is preferable to be thin than to be alive, sufficient to distort capacity? ${ }^{10}$ And what of individuals with personality disorders, whose suicidal behaviour is often a powerful form of communication that is an expression of distorted internal representations of relationships? We are required to do all we can to support patients in making decisions, but it is also necessary to take account of the gravity and irreversibility of decisions that shorten life. A debate needs to be had about how high the mental capacity bar should be set to end one's life by suicide.

Given the potentially diverse views on the stringency of a mental capacity test for assisted suicide, difficulties might be compounded if psychiatrists opposed to a change in legislation were conscientious objectors and refused to be involved in the process of capacity assessment. Those remaining might be more enthusiastic in their views of assisted suicide and might perhaps set the bar lower. ${ }^{11}$ If a new law were to be passed, it would be necessary for legislators to understand the complexity of these issues and issue appropriate guidance.

\section{Response shift}

Another way in which psychiatrists may inform the debate is around the phenomenon of 'response shift'. In the cancer journey, distress at the early stages often remits as patients adapt. ${ }^{12}$ Desire for death is strongly influenced by potentially reversible symptoms such as pain and depression. ${ }^{13}$ Likewise, as psychiatrists, we often see patients over long periods of time, and see their distress and suicidality fluctuate. Many of us will have had the experience of seeing someone who has taken an overdose swearing that they want to die. However, despite this, only about $1-2 \%$ of those who make suicide attempts end their lives within the next year. ${ }^{14}$ Much changes over time. There is a clear risk that professionals, in staying the hand of those desiring a change in the law, are characterised as paternalistic or self-interested, ${ }^{15}$ and that this accusation, in an increasingly democratised health system, potentially silences practitioners who may have genuine concerns about legal changes. We suggest that this first-hand clinical experience is pertinent and valuable. It is noteworthy that surveys have repeatedly shown that doctors working closest with the dying are those with the strongest objections to changes in the law, ${ }^{16}$ and this has also been found to be independent of religiousness and specialty. ${ }^{17}$ Our own clinical experiences preclude us from supporting a change in the law because we have seen suicidal patients who have expressed a strong desire for death change their views with high-quality palliative care. The remaining weeks and months of their lives have rarely lacked meaning for them or their families.

We suggest that, as clinicians used to dealing with patients, many of whom experience unbearable suffering, may lack capacity for certain decisions and frequently hold strong but fluctuating suicidal desires, psychiatrists are uniquely placed to inform the debate, even if we are unable to reach a consensus.

Matthew Hotopf, PhD, MRCPsych, william Lee, MSC, MRCPsych, Annabel Price, MRCPsych, Department of Psychological Medicine, Institute of Psychiatry, King's College London, UK

Correspondence: Professor Matthew Hotopf, Department of Psychological Medicine, Institute of Psychiatry, King's College London, Weston Education Centre, 10 Cutcombe Road, London SE5 9RJ, UK. Email: matthew.hotopf@ kcl.ac.uk

First received 10 Jun 2010, accepted 15 Sep 2010

\section{References}

1 Siddique H. Man who helped partner die calls for assisted suicide law change. Guardian 2009; 15 June (http://www.guardian.co.uk/society/2009/ jun/15/assisted-suicide-dignitas-cutkelvin-laws).

2 The Scottish Parliament. End of Life Assistance (Scotland) Bill (SP 38). The Scottish Parliament, 2010 (http://www.scottish.parliament.uk/s3/bills/ 38-EndLifeAssist/index.htm).

3 BBC News. Lords block assisted dying bill. BBC News 2006; 12 May (http://news.bbc.co.uk/1/hi/health/4763067.stm).

4 BBC. Latest: Assisted Dying Bill. BBC, 2009 (http://www.bbc.co.uk/ethics/ euthanasia/overview/asstdyingbill_1.shtml).

5 Starmer K. Policy for Prosecutors in Respect of Cases of Encouraging or Assisting Suicide. The Crown Prosecution Service, 2010 (http:// www.cps.gov.uk/publications/prosecution/assisted_suicide_policy.html).

6 Seale C. Doctors and assisted suicide. Do it properly or not at all. BMJ 2010; 340: $\mathrm{C1719.}$

7 Smith WR, Noonan C, Buchwald D. Mortality in a cohort of chronically fatigued patients. Psychol Med 2006; 36: 1301-6.

8 Santhouse AM, Hotopf M, David AS. Chronic fatigue syndrome. BMJ 2010; 340: $\mathrm{c738}$.

9 Dickenson DL, Fulford B. In Two Minds: A Casebook of Psychiatric Ethics. Oxford University Press, 2000.

10 Tan DJ, Hope PT, Stewart DA, Fitzpatrick PR. Competence to make treatment decisions in anorexia nervosa: thinking processes and values. Philos Psychiatr Psychol 2006; 13: 267-82.

11 Ganzini L, Leong GB, Fenn DS, Silva JA, Weinstock R. Evaluation of competence to consent to assisted suicide: views of forensic psychiatrists. Am J Psychiatry 2000; 157: 595-600.

12 Burgess C, Cornelius V, Love S, Graham J, Richards M, Ramirez A. Depression and anxiety in women with early breast cancer: five year observational cohort study. BMJ 2005; 330: 702.

13 Chochinov HM, Wilson KG, Enns M, Mowchun N, Lander S, Levitt M, et al. Desire for death in the terminally ill. Am J Psychiatry 1995; 152: 1185-91.

14 Owens D, Horrocks J, House A. Fatal and non-fatal repetition of self-harm. Systematic review. Br J Psychiatry 2002; 181: 193-9.

15 Warnock M, Macdonald E. Easeful Death: Is There a Case for Assisted Dying? Oxford University Press, 2009.

16 Seale C. Legalisation of euthanasia or physician-assisted suicide: survey of doctors' attitudes. Palliat Med 2009; 23: 205-12.

17 Lee W, Price A, Rayner L, Hotopf M. UK doctors' attitudes to the legalisation of assisted suicide. Palliat Med 2009; 23: 570. 